\title{
Caracterização isoenzimática de clones de bananeira nanicão submetidos à salinidade ${ }^{1}$
}

\author{
Cláudia Ulisses ${ }^{2}$, Terezinha R. Camara ${ }^{3}$, Lilia Willadino ${ }^{4}$, Cynthia C. de Albuquerque ${ }^{2}$, \\ Luíza S. S. Martins ${ }^{4} \&$ Nara S. A. de Freitas ${ }^{4}$

\begin{abstract}
1 Parte da Dissertação de Mestrado do primeiro autor, apresentada à UFRPE
2 UFRPE. Programa de Pós-graduação em Botânica. Rua Dom Manoel de Medeiros, s/n, CEP 52171-900, Recife, PE. Fone: (81) 3302-13 64. E-mail: claudia@nlink.com.br (Foto)

3 UFRPE. Depto. de Química. Fone: (81) 3302-1364. E-mail: tcamara@novaera.com.br.

${ }^{4}$ UFRPE. Depto. de Biologia. Fone: (81) 3302-1366. E-mail: lilia@truenet.com.br
\end{abstract}

Protocolo $123-15 / 8 / 2001$

\begin{abstract}
Resumo: O presente trabalho teve o objetivo de identificar possíveis variações isoenzimáticas em plantas de bananeira, provenientes de gemas da cultivar nanicão, submetidas à pressão de seleção in vitro, com 80 e $100 \mathrm{~mol} \mathrm{~m}^{-3}$ de $\mathrm{NaCl}$. Após aclimatadas, as plantas foram transferidas para solo com diferentes níveis de salinidade do extrato de saturação do solo (CEe de 0,2, 7,0 e 14,0 dS $\mathrm{m}^{-1}$ ) e cultivadas, durante 30 dias, em casa-de-vegetação. Em solo com CEe de 14,0 $\mathrm{dS} \mathrm{m}^{-1}$ as plantas não resistiram à salinidade. Dos sistemas isoenzimáticos analisados, apenas o sistema peroxidase apresentou atividade em todas as amostras de tecido foliar analisadas. As plantas regeneradas a partir de gemas submetidas ao estresse salino in vitro, apresentaram bandas anódicas e catódicas nos tratamentos com 0,2 e 7,0 dS $\mathrm{m}^{-1}$, enquanto as plantas provenientes de gemas não tratadas em meio salino, apresentaram apenas bandas catódicas. Alterações em número e intensidade de bandas isoenzimáticas podem ser decorrentes de variações somaclonais induzidas pelo estresse salino imposto durante o cultivo in vitro.
\end{abstract}

Palavras-chave: Musa spp, isoenzimas, peroxidase, variação somaclonal

\section{Isoenzyme characterization of the clones of banana nanicão subjected to salinity}

\begin{abstract}
This study is aimed to identify isoenzimatic variations in banana plants derived from buds of cultivar nanicão subjected to in vitro selection with 80 and $100 \mathrm{~mol} \mathrm{~m}^{-3}$ of $\mathrm{NaCl}$. After acclimatization, plants were cultivated for 30 days in a greenhouse, under different levels of soil salinity of saturation extracts $\left(E C e=0.2,7.0\right.$ and $\left.14.0 \mathrm{dS} \mathrm{m}^{-1}\right)$. Plants cultivated in soil with $14.0 \mathrm{dS} \mathrm{m}^{-1}$ did not resist the stress. Among the isoenzimatic systems evaluated, only peroxidase system showed activity in all the leaf samples. Plants regenerated from buds subjected to in vitro saline stress presented anodic and cathodic bands for treatments with 0.2 and $7.0 \mathrm{dS} \mathrm{m}^{-1}$, while plants formed from buds grown on salt free medium showed only cathodic bands. Alterations of band number and intensity could be due to somaclonal variation induced by salt stress during in vitro culture.
\end{abstract}

Key words: Musa spp, isoenzymes, peroxidase, somaclonal variation

\section{INTRODUÇÃO}

A banana (Musa spp.) é a fruta de preferência mundial, motivo pelo qual se constitui numa das culturas mais exploradas no mundo e assume importância fundamental, pelo seu valor econômico e social. No Brasil, a região Nordeste é responsável por $38,52 \%$ da produção nacional de banana (Anuário Estatístico Brasileiro, 1997). Nos últimos anos, entretanto, tem sido registrada queda na produção dessa frutífera, em decorrência de diversos fatores, dentre eles a salinização do solo provocada, em maior parte, pela irrigação. Nas regiões áridas e semi-áridas o cultivo irrigado é uma alternativa para garantir a produção no período da estiagem, mas o manejo inadequado do solo e da água pode resultar na salinização das terras antes produtivas. O desenvolvimento da bananeira é reduzido quando o cultivo é realizado em solos com condutividade elétrica do extrato saturado (CEe) maior que $3,0 \mathrm{dSm}^{-1}$ (Israeli et al., 1986). Uma alternativa que possibilita a expansão do cultivo em áreas com problema de salinização, é a obtenção de cultivares adaptadas à essas condições.

O melhoramento de cultivares de bananeira de importância econômica visando a tolerância à salinidade do solo, depara-se com a esterilidade das cultivares comerciais, razão pela qual a técnica de seleção in vitro surge como alternativa biotecno- 
lógica, uma vez que pode promover o aumento da variabilidade genética na forma de variantes somaclonais. A variação somaclonal tanto pode surgir a partir de fatores preexistentes na planta, como ser induzida durante a fase de cultivo in vitro. Essas variações podem determinar alterações no fenótipo e/ou genótipo dos indivíduos resultantes, podendo ser detectadas a partir de análise isoenzimática e de outros marcadores moleculares (Evans \& Sharp, 1986; Skirvin et al., 1994).

Os sistemas isoenzimáticos constituem importante ferramenta bioquímica na identificação de híbridos interespecíficos e de variantes genéticos, bem como na detecção de alterações gênicas em plantas provenientes do cultivo in vitro. A presença ou ausência de bandas, assim como modificações na intensidade das mesmas, auxiliam de forma significativa na diferenciação isoenzimática de plantas (Jarret \& Litz, 1986).

Variações nos padröes dos sistemas isoenzimáticos da peroxidase são freqüentes em plantas submetidas a estresses abióticos. O incremento da atividade dessas enzimas antioxidantes é fundamental para evitar danos a nível celular, provocados por espécies ativas de oxigênio (Sreenivasulu et al., 1999). O peróxido de hidrogênio $\left(\mathrm{H}_{2} \mathrm{O}_{2}\right)$ é seqüestrado pelas peroxidases e decomposto por meio da oxidação de cosubstratos, como compostos fenólicos e/ou antioxidantes (Dionísio-Sese \& Tobita, 1998). Plantas com altos níveis de antioxidantes, constitutivos ou induzidos, são reportadas como mais tolerantes a danos oxidativos (Dionísio-Sese \& Tobita, 1998; Sreenivasulu et al., 1999).

O objetivo deste trabalho foi identificar possíveis variações isoenzimáticas em plantas de bananeira nanicão, provenientes de gemas submetidas à pressão de seleção in vitro, com $80 \mathrm{e}$ $100 \mathrm{~mol} \mathrm{~m}^{-3} \mathrm{de} \mathrm{NaCl}$.

\section{MATERIAL E MÉTODOS}

Trinta plantas de bananeira (Musa spp) provenientes de gemas submetidas à pressão de seleção in vitro com $80 \mathrm{e}$ $100 \mathrm{~mol} \mathrm{~m}^{-3} \mathrm{de} \mathrm{NaCl}$ (Ulisses et al., 2000) e plantas micropropagadas em meio sem adição de $\mathrm{NaCl}$ (tratamento controle) foram transplantadas para potes plásticos, com capacidade para $300 \mathrm{~mL}$, contendo uma mistura de solo e vermiculita (2:1) e aclimatadas em telado com sombrite $70 \%$, pelo período de $30 \mathrm{~d}$. Após a aclimatação, as 30 plantas foram transferidas e mantidas, durante $30 \mathrm{~d}$, em casa-de-vegetação. Foram estabelecidos três tratamentos, em função da condutividade elétrica do extrato saturado do solo (CEe: 0,2; 7,0 e 14,0 $\mathrm{dS} \mathrm{m}^{-1}$ ). A combinação desses níveis de salinidade do solo com os níveis de salinidade do meio seletivo $\left(0,80\right.$ e $100 \mathrm{~mol} \mathrm{~m}^{-3}$ de $\mathrm{NaCl}$ ) do qual as plantas procediam, totalizaram 9 tratamentos. Foram mantidas 3 repetições nos tratamentos em solo com CEe de 0,2 e 7,0 dS m${ }^{-1}$, totalizando nove plantas em cada nível de salinidade, e 4 repetições no tratamento com CEe de 14,0 dS m ${ }^{-1}$, totalizando 12 plantas. Após o período experimental, coletaram-se amostras de tecido foliar das plantas sobreviventes, para realização de análises isoenzimáticas.

Amostras de folhas jovens $(0,5 \mathrm{~g})$ foram maceradas, individualmente, até total homogeneização, em presença de $1,5 \mathrm{~mL}$ de uma solução extratora composta pelos tampões borato de lítio e triscitrato, além de $300 \mathrm{mg}$ de sacarose e 300 mg de polyvinylpyrrolidone (PVP). Após a homogeneização, os extratos foram colocados em tubos "eppendorf" e centrifugados a $12.000 \mathrm{x}$ g durante $10 \mathrm{~min}, \mathrm{a} 4{ }^{\circ} \mathrm{C}$; em seguida, segmentos de papel Whatman oㅡ 3, medindo $0,4 \times 0,5 \mathrm{~cm}^{2}$, foram embebidos nos extratos das amostras e aplicados em gel de poliacrilamida a 7\% (Scandalios, 1969) em sistema de eletroforese horizontal e descontínuo. Após a aplicação das amostras nos géis, os retângulos de papel Whatman foram marcados com azul de bromofenol ( $1 \% \mathrm{~m} / \mathrm{v}$ em álcool etílico); nas cubas, utilizaram-se soluções-tampão borato de lítio e triscitrato. Os géis foram postos a migrar a uma temperatura aproximada de $4{ }^{\circ} \mathrm{C}$, até que a linha de frente atingisse $9 \mathrm{~cm}$ do ponto de aplicação das amostras. Durante a migração, utilizouse uma corrente de $9,0 \mathrm{v} \mathrm{cm}^{-1}$ e, após a corrida eletroforética, efetuou-se a revelação específica das proteínas para cada sistema isoenzimático. Foram analisados os sistemas peroxidase (POX), esterase (EST), fosfatase ácida (ACP) e glutamato oxaloacetato transaminase (GOT). Os protocolos de revelação foram baseados nos trabalhos de Poulik (1957) para POX e GOT, e de Scandalios (1969) para EST e ACP. Posteriormente, avaliou-se o número, a intensidade e a mobilidade relativa das bandas isoenzimáticas reveladas para a definição dos padrões das amostras utilizadas. Os valores de mobilidade relativa das bandas foram calculados dividindo-se a distância percorrida pela molécula protéica, desde o ponto de aplicação da amostra até a linha de frente, sendo o resultado multiplicado por 100 (Alfenas et al., 1991).

\section{RESULTADOS E DISCUSSÃO}

As 12 plantas submetidas ao cultivo em solo salino com CEe de 14,0 dS m ${ }^{-1}$, não sobreviveram por mais de 7 dias ao tratamento salino. Por outro lado, das 9 plantas mantidas em solo com CEe de 7,0 dS m ${ }^{-1}$, apenas três sobreviveram, das quais 2 provinham da seleção in vitro com $80 \mathrm{~mol} \mathrm{~m}^{-3} \mathrm{de} \mathrm{NaCl}$ e uma era proveniente da seleção com $100 \mathrm{~mol} \mathrm{~m}^{-3}$ de $\mathrm{NaCl}$ (Tabela 1).

Tabela 1. Relação dos clones sobreviventes após 30 dias de cultivo em solo salino ( $\left.7,0 \mathrm{dS} \mathrm{m}^{-1}\right)$ e não salino $\left(0,2 \mathrm{dS} \mathrm{m}^{-1}\right)$

\begin{tabular}{ccc} 
Genótipos & $\begin{array}{c}\text { Pressão de Seleção } \\
\text { in vitro }\left(\mathrm{mol} \mathrm{m}^{-3} \mathrm{NaCl}\right)\end{array}$ & $\begin{array}{c}\mathrm{CEe}^{*} \\
\left.(\mathrm{dS} \mathrm{m})^{-1}\right)\end{array}$ \\
\hline A & 80 & 0,2 \\
B & 100 & 0,2 \\
C & 80 & 0,2 \\
D & 80 & 7,0 \\
E & 80 & 7,0 \\
F & 100 & 0,2 \\
G & 100 & 7,0 \\
T (controle) & 0 & 0,2 \\
\hline
\end{tabular}

CEe: Condutividade elétrica do extrato saturado do solo

Alguns clones apresentaram sintomas de estresse salino e osmótico, tais como amarelecimento das bordas do limbo foliar e murcha das folhas, após 25 dias de cultivo em solo com a CEe de 7,0 dS m $\mathrm{m}^{-1}$. Esses sintomas foram bastante reduzidos no clone $\mathrm{G}$, o qual foi procedente da pressão de seleção in vitro com $100 \mathrm{~mol} \mathrm{~m}^{-3} \mathrm{de} \mathrm{NaCl}$. 
No que se refere à análise dos sistemas isoenzimáticos $\mathrm{ACP}$ e GOT, não se constatou atividade nas amostras das plantas que sobreviveram ao tratamento salino com CEe de 7,0 $\mathrm{dS} \mathrm{m}^{-1}$, nem naquelas do tratamento com $0,2 \mathrm{dS} \mathrm{m}^{-1}$. O sistema EST revelou-se com baixa intensidade de coloração, comportamento que conflita com os resultados de Bhat et al. (1992a) que observaram adequada resolução desse sistema em cultivares triplóides de bananeira, provenientes do cultivo in vivo, em ausência de $\mathrm{NaCl}$. Esses resultados divergentes podem estar relacionados a variações resultantes do próprio processo de cultivo in vitro, fato este também comentado por Freitas (1997).

$\mathrm{O}$ sistema peroxidase apresentou atividade em todas as amostras analisadas, fenômeno também constatado por Bhat et al. (1992b) em bananeira triplóide cultivada in vitro. Jarret \& Litz (1986) também apontam o sistema peroxidase como aquele de melhor resolução, permitindo distinguir entre diferentes grupos genômicos e entre cultivares de bananeira. Esse sistema isoenzimático pode ser utilizado, também, como indicador fisiológico de plantas estressadas por fatores bióticos ou abióticos (Lagrimini et al., 1990; Sherf \& Kolattukudy, 1993). No presente trabalho, a presença de bandas de mobilidade catódica (POX 1 e POX 2) foi detectada exclusivamente nos somaclones selecionados in vitro, como tolerantes ao $\mathrm{NaCl}$ (Figura 1). A expressão específica de uma banda de peroxidase em genótipo tolerante à salinidade, também foi constatada em Setaria italica (Sreenivasulu et al., 1999). Além da presença de bandas de peroxidase exclusivas, é freqüente observar-se o aumento da atividade das peroxidases em cultivares tolerantes, como relatado para Setaria italica (Sreenivasulu et al., 1999) e Morus alba (Sudhakar et al., 2001). Trabalhos realizados com

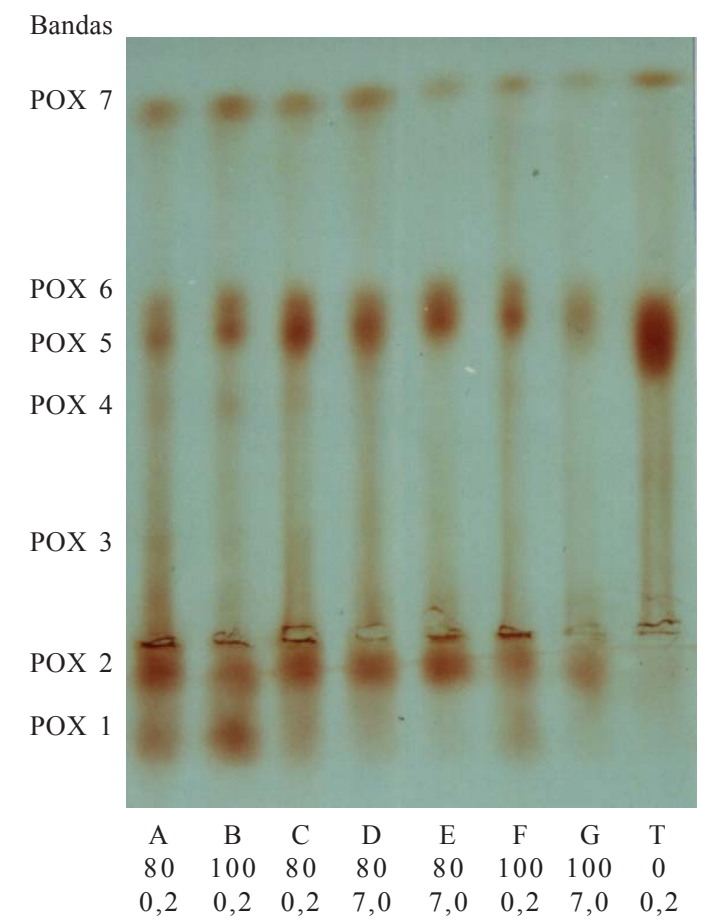

Figura 1. Padrões eletroforéticos de peroxidase (POX) do tecido foliar de plantas de bananeira provenientes de gemas submetidas à pressão de seleção in vitro com $\mathrm{NaCl}(80 \mathrm{e}$ $100 \mathrm{~mol} \mathrm{~m}^{-3}$ ), e cultivadas em solo salinizado (CEe de 7,0 $\mathrm{dS} \mathrm{m}^{-1}$ ) e não salinizado (CEe de $0,2 \mathrm{dS} \mathrm{m}^{-1}$ ) suspensões celulares de Licopersicon esculentum adaptadas ao $\mathrm{NaCl}$ registraram o aumento da atividade das peroxidases inclusive no meio de cultura (Sancho et al., 1996). O incremento da atividade das enzimas peroxidases é fundamental no controle da ação de espécies de oxigênio reativas responsáveis pelo desequilíbrio metabólico decorrente de danos oxidativos a lipídios, proteínas e ácidos nucléicos, comuns em condições de estresse salino (Dionisio-Sese \& Tobita, 1998; Sreenivasulu et al., 1999; Yoshimura et al., 2000).

A diversidade na intensidade de coloração e na quantidade de bandas observadas neste trabalho é decorrente, provavelmente, de variações somaclonais ocorridas durante o processo de seleção in vitro. Tais diferenças confirmam a eficiência do processo seletivo utilizado in vitro, proporcionando o aumento de variabilidade gênica (Evans \& Sharp, 1986) em clones de bananeira. A obtenção de variante somaclonal a partir de pressão de seleção in vitro já foi registrada para outras espécies, como a cultivar Andro flax de Linum usitatissimum (Rowland et al., 1989) que apresenta maior tolerância a ambientes salinos, e a cultivar GAC102 de Sorghum bicolor (Duncan et al., 1991) com tolerância a solos ácidos.

\section{CONCLUSÕES}

1. A pressão de seleção in vitro com 80 e $100 \mathrm{~mol} \mathrm{~m}^{-3}$ de $\mathrm{NaCl}$, promoveu a tolerância de plantas de bananeira nanicão ao cultivo, por 30 dias, em solo com CEe de $7,0 \mathrm{dS} \mathrm{m}^{-1}$.

2. Dentre os sistemas analizados o peroxidase foi o mais sensível às variações decorrentes da pressão de seleção in vitro com $\mathrm{NaCl}$.

3. A presença de bandas anódicas do sistema isoenzimático peroxidase registrou-se exclusivamente em plantas oriundas de gemas submetidas à pressão de seleção com $\mathrm{NaCl}$.

\section{LITERATURA CITADA}

Alfenas, A.C.; Peters, I.; Brune, W. Eletroforese de proteínas isoenzimas de fungos e essências vegetais. Viçosa: UFV, 1991.243p.

Anuário Estatístico Brasileiro. Rio de Janeiro: IBGE, 1997. np.

Bhat, K.V.; Bhat, S.R.; Chandel, K. P.S. Survey of isoenzyme polymorphism for clonal identification in Musa. I Esterase, acid phosphatase and catalase. Journal of Horticultural Science, Ashford Kent, v.67, p.501-507, 1992a.

Bhat, K.V.; Bhat, S.R.; Chandel, K.P.S. Survey of isoenzyme polymorphism for clonal identification in Musa: II. Peroxidase, superoxide dismutase, shikimate dehydrogenase and malate dehydrogenase. Journal of Horticultural Science, Ashford Kent, v.67, p.737-743, 1992b.

Dionisio-Sese, M.L.; Tobita, S.; Antioxidant responses of rice seedlings to salinity stress. Plant Science, Strasbourg, v.135, p.1-9, 1998.

Duncan, R.R.; Washom, R.M.; Miller, D.R.; Voigt, G.E.; Hanning, G.E.; Timm D.; Nabors, M.W. Registration of GAC 102: Acid soil tolerant hegari regenerant. Crop Science, Madison, v.31, p.1396-1397, 1991. 
Evans, D.A.; Sharp, W.R. Somaclonal and gametoclonal variation. In: Evans, D.A.; Sharp, W.R.; Ammirato, P.V. (Ed.). Handbook of plant cell culture. New York: MacMillan Publishing, v.4, p.97-132, 1986.

Freitas, N.S.A., Avaliação de Pennisetum purpureum Schum. e seus híbridos com P. americanum (L.) Leeke, mediante padrões isoenzimáticos e variáveis morfofisiológicas. Recife: UFRPE, 1997. 102p. Dissertação Mestrado

Israeli, Y.; Lahav, E.; Nameri, N. The effect of salinity and sodium absorption ratio in the irrigation water on growth and productivity of bananas under drip irrigation conditions. Fruits, Paris, v. 41, p.297-302, 1986.

Jarret, R.L.; Litz, R.E. Isoenzymes as genetic markers in bananas and plantains. Euphytica, Dordrecht, v.35, p.539-549, 1986.

Lagrimini, L.M.; Bradfords, S.; Rothstein, S. Peroxidase: Induced wilting in transgenic tobacco plants. The Plant Cell, Baltimore, v.2, p.7-18, 1990.

Poulik, M.D. Starch gel eletrophoresis in a discontinuous system buffers. Nature, London, v.180, p.1477-1479, 1957.

Rowland, G.G.; McHughen, A.; Bhatty, R.S. Andro flax. Canadian Journal of Plant Science, Ottawa, v.69, p.911-913, 1989.

Sancho, M.A.; Forchetti, S.M.; Pliego, F.; Valpuesta, V.; Quesada, M.A. Peroxidase activity and isoenzymes in the culture medium of $\mathrm{NaCl}$ adapted tomato suspension cells. Plant Cell, Tissue and Organ Culture, Dordrecht, v.44, p.161-167, 1996.
Scandalios, J.G. Genetic control of multiple molecular forms of enzymes in plants: A review. Biochemical Genetics, New York, v. 3, p.33-39, 1969.

Sherf, B.A.; Kolattukudy, P.E. Developmentally regulated expression of the wound-and pathogen-responsive tomato anionic peroxidase in green fruit. Plant Journal, Stuttgard, v.3, p.829-933, 1993.

Skirvin, R.M.; McPheeters, K.D.; Norton, M. Sources and frequency of somaclonal variation. Journal of Horticultural Science, Ashfort Kent, v.29, p.513-519, 1994.

Sreenivasulu N.; Ramanjulu, S.; Ramachandra-Kini, K.; Prakash, H. S.; Shekar-Shetty, H.; Savithri, H. S.; Sudhakar, C. Total peroxidase activity and peroxidase isoforms as modified by salt stress in two cultivars of fox-tail millet with differential salt tolerance. Plant Science, Strasbourg, v.141, p.1-9, 1999

Sudhakar, C.; Lakshmi, A.; Giridarakumar, S. Changes in the antioxidant enzyme efficacy in two high yielding genotypes of mulberry (Morus alba L.) under $\mathrm{NaCl}$ salinity. Plant Science, Strasbourg, v.161, p.613-619, 2001.

Ulisses, C.; Camara, T.R.; Rocha, P.S.G. da; Willadino, L.; Albuquerque, C.C.; Meunier, I. Seleção in vitro de gemas de bananeira Nanicão tolerantes à salinidade. Scientia Agrícola, Piracicaba, v.57, p.667-670, 2000.

Yoshimura, K.; Yabuta, Y.; Ishikawa, T.; Shigeoka, S. Expretion of spinach ascorbate peroxidase isoenzymes in response to oxidative stresses. Plant Physiology, Rockville, v.123, p.223-233, 2000. 